\title{
METODE PENYAPIHAN VENTILASI MEKANIK DI INTENSIVE CARE UNIT : STUDI LITERATUR
}

\author{
Sarinti ${ }^{1}$, Reni Sulung Utami ${ }^{2}$, Awal Prasetyo ${ }^{3}$ \\ Universitas Diponegoro, Semarang \\ Email:sari.icu14@gmail.com
}

\begin{abstract}
ABSTRAK
Latar belakang : Pasien di ICU ( Intensive Care Unit ) yang membutuhkan bantuan ventilasi mekanik hampir mencapai 30\% dari total pasien. Ventilasi mekanik yang digunakan dalam jangka panjang dapat meningkatkan resiko terjadinya mortalitas, dan ventilator associated pneumonia sehingga diperlukan perencanaan penyapihan yang tepat. Tujuan : Studi literatur ini bertujuan untuk mengidentifikasi metode penyapihan pasien dari ventilasi mekanik di ICU. Metode : Penelusuran literatur dilakukan melalui database Google scholar dan Google search dengan menggunakan kata kunci weaning mechanical ventilation, weaning protocol, critical care nursing. Literatur yang digunakan dari tahun 1997-2015 dalam bentuk full text. Literatur yang sesuai kriteria inklusi dan eksklusi dianalisis secara narasi. Hasil: Penelusuran mendapatkan 7 artikel penelitian yang menunjukkan metode penyapihan pasien dari ventilasi mekanik. Metode penyapihan dari ke 7 artikel tersebut adalah metode protokol dan non protokol. Metode non protokol misalnya physician direct weaning ( PDW ) dan collaboration weaning plan ( CWP ). Metode penyapihan dengan protokol antara lain : nurse' protokol directed weaning ( NPDW) dan protokol base weaning ( PBW ). Kesimpulan : Metode penyapihan protokol menunjukkan hasil lebih efektif dibandingkan metode non protokol.
\end{abstract}

Kata Kunci: Penyapihan Ventilasi Mekanik, Protokol Penyapihan, Keperawatan Kritis

\section{Methode of Weaning from Mechanical Ventilation in Intensive Care Unit : Study Literature}

\begin{abstract}
Back ground : patients in the ICU who require mechanical ventilation assistance almost $30 \%$ of the total patients. Mechanical ventilation is used in the long term can increase the risk of mortality and ventilator associated pneumonia so that proper planning is necessary weaning. Objectives : the literature study aims to identify methods of weaning patients from mechanical ventilation in the ICU. Methods : the literature study search pass through by Google scholar and Google search using keywords weaning mechanical ventilation, weaning protocol, critical care nursing. Literature is used from the year 1997-2015 in the form of full text. Appropriate literature inclusion and exclusion criteria were analyzed narrative. Results : search get 7 articles studies showing methods of weaning patients from mechanical ventilation. Method of weaning to the article 7 is the method protocol and non-protocol. Methods of non protocols eg physician-direct weaning ( PDW ) and collaboration weaning plan ( CWP ). Methods of weaning protocols include: nurse protocol directed weaning (NPDW) and protocols base weaning ( PBW ). Conclusion : the method of weaning protocol shows the results more effective than non - protocol methods
\end{abstract}

Key word : weaning mechanical ventilation; weaning protocol; critical care nursing 


\section{Pendahuluan}

Ventilasi mekanik merupakan alat bantu pernapasan yang digunakan pada pasien yang mengalami gagal nafas. ${ }^{1}$ Pasien gagal nafas ditandai parameter abnormal hasil analisa gas darah antara lain : $\mathrm{pH}<7.25, \mathrm{PaCO}_{2}>50 \mathrm{mmHg}$ dan $\mathrm{PaO}_{2}<50 \mathrm{mmHg}$. Ventilasi mekanik sering digunakan pada sekitar $30 \%$ pasien yang mengalami masalah kegawatan pernafasan di perawatan intensif. Penggunaan ventilasi mekanik dalam jangka panjang dapat meningkatkan resiko infeksi nosokomial, pneumonia dan kematian. ${ }^{2}$

Penyapihan merupakan proses penghentian bantuan ventilasi mekanik dan pelepasan jalan nafas buatan. ${ }^{3}$ Keberhasilan penyapihan dari ventilasi mekanik ditentukan dari ketepatan pengambilan keputusan klinik berdasarkan parameter tertentu, antara lain proses penyakit, $\mathrm{PaO} 2$, $\mathrm{PEEP}, \mathrm{FiO} 2, \mathrm{pH}, \mathrm{Hb}$, kesadaran, suhu tubuh, fungsi jantung, fungsi paru, jalan napas, obat - obatan agen sedative atau agen paralisis, fisiologis serta psikologis pasien. Penyapihan dilakukan sejak penyakit penyebab gagal nafas teratasi, hasil analisa gas darah normal, pernafasan spontan cukup adekuat, dan bantuan minimal dari ventilasi mekanik. ${ }^{2}$

Pada proses penyapihan akan ditemukan beberapa permasalahan, antara lain : simple weaning, difficult weaning dan prolonged weaning. Proses penyapihan dari ventilasi mekanik merupakan masalah yang kompleks, sehingga perlu perencanaan dengan metode yang tepat. ${ }^{3}$

Perawat sebagai care giver dan bekerja full time mempunyai peranan penting dalam memutuskan ketepatan program penyapihan. Perawat di area perawatan kritis memiliki kompetensi terkait pengelolaan pasien dengan ventilasi mekanik, namun saat ini belum memiliki kewenangan untuk mengambil keputusan klinis terkait perubahan mode setting pada ventilasi mekanik. ${ }^{4-6}$

Penulisan studi literatur ini bertujuan untuk mengidentifikasi metode penyapihan dari ventilasi mekanik di ruang intensive care unit.

\section{Metode}

Rancangan penelusuran artikel pada studi literatur ini melaui Google scholar dan Google search, dengan kata kunci weaning mechanical ventilation, weaning protocol, critical care nursing. Penelusuran tersebut mendapatkan 7 artikel yang sesuai kriteria inklusi dan eksklusi, antara lain artikel terbit tahun 1997-2013, bentuk full text dan design yang digunakan RCT, experimen, prospetive kohort dan prospective non randomized. Artikel yang sudah sesuai kriteria, kemudian dianalisa secara narasi.

\section{Hasil}

Karakteristik data dari penelusuran 7 artikel penelitian tersebut dapat dilihat pada tabel 1 . Ada beberapa metode penyapihan dari ventilasi mekanik yang ditemukan yaitu ${ }^{7-13}$ :

\section{Physician direct weaning ( PDW )}

Metode PDW merupakan metode weaning non protocolized, dimana tahapan weaning diatur oleh dokter dan dilakukan oleh perawat. Metode ini dilakukan dengan cara merubah mode misalnya PCV, PSIMV, CPAP / SPONT dan T-piece berdasarkan kriteria weaning. Keputusan ekstubasi juga dilakukan oleh dokter. Hal ini dilakukan flexible sesuai instruksi dokter. Ada hambatan dalam pelaksanaan metode ini karena ada keterbatasan waktu memonitor perubahan kondisi pasien, belum ada intensivist full time. Penelitian di Washington membandingkan protocol-based weaning dengan non protocol hasilnya 
menunjukkan PBW signifikan memperpendek durasi pemakaian ventilasi mekanik dibandingkan PDW, $\mathrm{p}=0.24$. Angka keberhasilan weaning $\mathrm{PBW}>\mathrm{PDW}, \mathrm{p}=0.39$. $^{7,8}$

\section{Collaboration weaning plan ( CWP )}

Metode CWP merupakan program weaning terkolaborasi dan melibatkan sistem multidisipliner. Metode ini melibatkan perawat, dokter, terapis, farmasi, gizi / nutrisionis, dan staf lain. Pengkajian persiapan weaning mencakup beberapa data ( $\mathrm{AGD}, \mathrm{ETCO}_{2}$, dan sebagainya ) dalam medical record, ringkasan program dibuat dipapan weaning dekat pasien dan catatan dokter. Metode ini ditentukan oleh tim, dipimpin oleh dokter. Perawat, terapis, dan dokter mencatat perkembangan proses weaning dalam lembar alur ( flow sheet ) dan weaning board yang ditaruh disisi pasien. Penelitian di Los Angeles membuktikan bahwa CWP dapat menurunkan lama rawat di ICU sampai 3.6 hari ( $\mathrm{p}=.03$ ), dan memperpendek waktu pemakaian ventilator sampai 2.7 hari $(\mathrm{p}=.06)$. Data terkait biaya perawatan dan komplikasi menunjukkan tidak ada perbedaan yang signifikan pada kedua kelompok. ${ }^{9}$

\section{Nurse` protocol directed weaning ( NPDW )}

Metode NPDW merupakan rekomendasi dari konsensus weaning protocol dari hasil penelitian di Perancis. Pasien yang akan dilakukan weaning diidentifikasi dengan nurses protocol - directed weaning procedure setiap hari. Skrining dilakukan segera setelah pasien masuk ICU dan memakai ventilasi mekanik > 24 jam. Kriteria Spontaneous Breathing trial meliputi : $\mathrm{PaO}_{2} / \mathrm{FiO}_{2}>200, \mathrm{FiO} 2<50 \%$, PEEP $\leq 5 \mathrm{cmH} 2 \mathrm{O}$, tanpa / minimal vasopresor, tanpa / minimal sedasi dan respon terhadap perintah sederhana. Perencanaan dilakukan dengan perubahan setting mode CPAP/SPONT yaitu PS diturunkan sampai $8 \mathrm{cmH} 2 \mathrm{O}$, PEEP $\leq 5 \mathrm{cmH} 2 \mathrm{O}$ selama 30 menit dilakukan 2 periode, dan jika toleransi dilanjutkan dapat dilakukan ekstubasi dengan persetujuan dokter. Jika melalui tahap SBT selama 5 - 90 menit menggunakan T-piece. Tahap SBT segera dihentikan, jika ada tanda intoleransi klinik, antara lain: $\mathrm{SpO}_{2}<90 \%$, RR $>35$ kali / mnt, nadi \& sistolik meningkat $>20 \%$, diaphoresis dan pasien gelisah. Perawat melakukan kolaborasi dan persetujuan dokter intensivist untuk kembali ke mode MV sebelumnya. Keberhasilan Spontaneous Breathing Trial ( SBT ) selama 90 menit dilanjutkan dengan kolaborasi untuk ekstubasi. ${ }^{10,13}$ Penelitian di Perancis menunjukkan adanya penurunan durasi pemakaian ventilasi mekanik ( $16.6 \pm 13$ hari vs $22.5 \pm 21$ hari ), LOS di ICU ( 21.6 \pm 14.3 hari vs 27.6 hari \pm 21.7 hari ) dan angka kematian hampir sama antara 2 kelompok tersebut. ${ }^{10,11}$ Penelitian lain di Korea membuktikan bahwa protocol based weaning (PBW) dapat memperpendek weaning time hingga 22 jam. ${ }^{12}$ 
Tabel 1.Karakteristik artikel $(\mathrm{N}=6)$

\begin{tabular}{|c|c|c|c|c|}
\hline No & Judul & Penulis/tahun & Metode & Hasil \\
\hline 1 & $\begin{array}{l}\text { A randomiszed control trial of protocol- } \\
\text { directed versus physician-directed } \\
\text { weaning from ventilation }\end{array}$ & Kollef, et.al (1997) & $\mathrm{RCT}$ & $\begin{array}{l}\text { PBW signifikan memperpendek durasi pemakaian ventilator } \\
\text { dibandingkan PDW } \mathrm{p}=0.24 \text {. Angka keberhasilan weaning } \\
\mathrm{PBW}>\mathrm{PDW}, \mathrm{p}=0.39\end{array}$ \\
\hline 2 & $\begin{array}{l}\text { Effect of collaborative weaning plan on } \\
\text { patient outcomes in critical setting }\end{array}$ & Elizabet H, et al (2001) & $\begin{array}{l}\text { Pre \& post quasi } \\
\text { experimental }\end{array}$ & $\begin{array}{l}\text { CWP menurunkan lama rawat di ICU } 3.6 \text { hari }(\mathrm{p}=.03) \text { dan } \\
\text { lama pemakaian ventilator } 2.7 \text { hari }(\mathrm{p}=.06) \text {. Tidak ada } \\
\text { perberbedaan signifikan terkait biaya diantara kedua } \\
\text { kelompok. }\end{array}$ \\
\hline 3 & $\begin{array}{l}\text { Impact nurses protocol-directed weaning } \\
\text { procedureon outcomes in patient } \\
\text { undergoing mechanical ventilation for } \\
\text { longer than } 48 \text { hours: a prospektif kohort } \\
\text { study with mached historical Control } \\
\text { group. }\end{array}$ & Tonnelier JM, et.al (2005) & Prospektif kohort study & $\begin{array}{l}\text { Durasi pemakaian ventilasi mekanik }(16.6 \pm 13 \text { hari : } \\
22.5 \pm 21 \text { hari; } \mathrm{p}=0.02) \text {, LOS }(21.6 \pm 14.3 \text { hari : } 27.6 \pm 21.7 \\
\text { hari; }=0.02) \text {, dan gagal ekstubasi dan kejadian VAP, } \\
\text { mortalitas dibanding antara kasus dan kontrol hasilnya } \\
\text { sama. }\end{array}$ \\
\hline 4 & $\begin{array}{l}\text { Protocolized vs non protocolized } \\
\text { weaning for reducing the duration of } \\
\text { mechanical ventilation in critically ill } \\
\text { adult patients: cochrane review protocol }\end{array}$ & Blackwood et.al. (2009) & Cochrane review & $\begin{array}{l}\text { Tenis outcome yang diukur: } \\
\text { Primer outcome; durasi pemakaian VM (waktu dalam } \\
\text { jam dari inisiasi sampai discontinu) } \\
\text { Skunder; mortalitas, reintubasi, quality of life, weaning } \\
\text { duration, LOS in ICU, dan biaya (cost) } \\
\text { Weaning protokol menunjukkan dapat mengurangi } \\
\text { durasi pemakaian ventilasi mekanik }\end{array}$ \\
\hline 5 & $\begin{array}{l}\text { Use of weaning protocols for reducing } \\
\text { duration of mechanical ventilation in } \\
\text { critically ill adult patient; cochrane } \\
\text { systematic review \& meta analysis }\end{array}$ & Blackwood, et. al. (2011) & Systematic review & $\begin{array}{l}\text { Dibandingkan dengan kebiasaan di ICU, Rerata geometric } \\
\text { durasi pemakaian VM pada grup weaning, adalah turun } \\
25 \% \text { (95\% confidence interval } 9 \% \text { to } 39 \%, \mathrm{p}=0.006 ; 10 \\
\text { trial), durasi weaning turun } 78 \% \text { ( } 31 \% \text { to } 93 \%, \mathrm{p}=0.009 ; 6 \\
\text { trials) dan LOS di ICU } 10 \% \text { ( } 2 \% \text { to } 19 \% ; \mathrm{p}=0.02 ; 8 \text { trials). }\end{array}$ \\
\hline 6 & $\begin{array}{l}\text { A weaning protocol administrered by } \\
\text { critical care nurses for the weaning of } \\
\text { patients from mechanical ventilation }\end{array}$ & Roh HJ, et.al ( 2012) & $\begin{array}{l}\text { A prospectictive, } \\
\text { randomized, control } \\
\text { trial. }\end{array}$ & $\begin{array}{l}\text { Tidak ada perbedaan antara } 2 \text { kelompok terkait } \\
\text { keberhasilan pasien lepas dari ventilator. Weaning time } \\
\text { lebih cepat pada kelompok PBW dibanding UC yaitu } 25 \\
\text { jam dibanding } 47 \text { jam. }\end{array}$ \\
\hline
\end{tabular}




\begin{tabular}{|c|c|c|c|c|}
\hline 7 & $\begin{array}{l}\text { Nurse-driven, protocol - directed } \\
\text { weaning from mechanical ventilation } \\
\text { improves clinical outcomes and is well } \\
\text { accepted by intensive care unit } \\
\text { physicians }\end{array}$ & Danckers M, et.al (2013) & $\begin{array}{l}\text { Prospective non } \\
\text { randomized }\end{array}$ & $\begin{array}{l}\text { Median durasi pemakaian ventilasi mekanik antara nurse } \\
\text { driven dan physician driven adalah } 2 \text { hari dan } 4 \text { hari, } \\
\mathrm{p}=.001 \text {. Median LOS di ICU pada nurse-driven dan } \\
\text { physicien -driven antara } 5 \text { dan } 7 \text { hari, } \mathrm{p}=.01 \text {. Waktu } \\
\text { ekstubasi lebih awal } 13 \text { menit pada kelompok nurse } \\
\text { driven, p<.001. Tidak ada perbedaan pada LOS di rumah } \\
\text { sakit, angka mortalitas, angka VAP dan kejadian } \\
\text { reintabasi pada kedua kelompok. }\end{array}$ \\
\hline
\end{tabular}

\section{PEMBAHASAN}

Berdasarkan hasil penelusuran ditemukan 2 metode penyapihan pasien dari ventilasi mekanik yaitu metode protokol dan non protokol. Penelitian di Korea dan negara berkembang lainnya menyebutkan bahwa hambatan dalam penerapan penyapihan non protokol dikarenakan belum mempunyai intesivist full time, sehingga inisiasi weaning berpotensi mengalami delay. ${ }^{12,14}$ Metode penyapihan tanpa protokol antara lain PDW dan CWP.

Metode PDW terdapat beberapa kekurangan antara lain : keterbatasan waktu observasi respon pasien, dan adanya potensi inkonsistensi dalam aplikasinya karena flexible misalnya : menurunkan modus setting tidak on time sesuai respon pasien saat itu. Metode tersebut hanya memberikan peran perawat sebatas pada observasi dan monitoring sampai ada instruksi baru untuk tahapan selanjutnya. Perawat tidak dapat memutuskan untuk menghentikan atau melanjutkan proses weaning karena tidak ada protokol tertulis, sehingga perubahan program weaning diluar visite dokter dapat dilakukan dengan cara konsultasi melalui telepon. Hal ini berpotensi terjadi delay dalam membuat keputusan inisiasi weaning. ${ }^{8,14}$

Beberapa hambatan metode CWP antara lain : melibatkan struktur tim spesialis dalam management approach, sering terjadi miskomunikasi antara perawat dan dokter dalam kolaborasi dan ketidaksetaraan dalam kompetensi klinik antara perawat dan dokter dalam pelatihan. ${ }^{9,}{ }^{15}$ Metode penyapihan yang banyak melibatkan peran perawat dalam proses pelaksanaannya adalah NPDW. Metode ini dilakukan berdasarkan protokol yang sudah baku sesuai evidence based. Protokol ini dalam bentuk protokol penyapihan kolaborasi perawat dan dokter. Perawat memiliki peran dan tanggung jawab dalam skrining harian untuk kesiapan weaning, observasi, monitoring, manajemen jalan nafas, mengurangi dukungan dari ventilasi mekanik dan merubah mode setting sesuai kriteria pada protokol. Dokter berperan mengatasi penyakit yang mendasari, pengelolaan masalah respiratory function, pengelolaan gagal weaning dan approval untuk ekstubasi / kembali ke support ventilation. ${ }^{10}$ 
Implikasi di Indonesia terkait metode penyapihan pasien dari ventilasi mekanik masih menerapkan metode non protokol. Keterbatasan dari literatur review ini hanya menemukan artikel penelitian yang dilakukan diluar negeri. Oleh karena itu untuk meningkatkan mutu pelayanan di ICU di Indonesia perlu diteliti tentang metode penyapihan dengan protokol.

\section{Kesimpulan}

Metode penyapihan pasien dari ventilasi mekanik ada 2, yaitu metode non protokol dan protokol. Metode penyapihan dengan protokol lebih efektif dalam memperpendek hari rawat di ICU, mengurangi durasi pemakaian ventilasi mekanik dan meningkatkan autonomy perawat intensif. Metode penyapihan tersebut melibatkan peran dokter, perawat dan terapis. Perawat bertugas full time dalam memberikan asuhan keperawatan di area kritis, sehingga banyak terlibat dalam pengelolaan pasien dengan ventilasi mekanik. Metode penyapihan yang banyak melibatkan peran perawat adalah metode penyapihan dengan protokol oleh perawat ( Nurse protocol-direct weaning ).

Pada perkembangan asuhan keperawatan kritis saat ini sangat diperlukan protokol penyapihan tertulis yang bertujuan untuk : mengurangi keterbatasan dan bias dalam pengambilan keputusan, sebagai dasar pengembangan bukti ilmiah, memperkecil mispresepsi antar staff, mengatasi keterbatasan waktu dan tenaga, memberi keleluasaan dokter untuk melakukan tugas lain di ICU, memfasilitasi kualitas monitoring dan meningkatkan transparansi komunikasi dan autonomy staff ICU dalam inisiasi weaning.

\section{Daftar Pustaka}

1. Morton PG, Fontaine D, Hudak CM, Galo BM. Keperawatan Kritis. Jakarta: EGC; 2013.

2. Sundana K. Ventilator: pendekatan praktis di Unit Perawatan Kritis. Vol 1. 1 ed. Bandung: CICU RSHS; 2008.

3. Alia I, Esteban A. Weaning from mechanical ventilation. Crit Care Med. 2000;4:72-80.

4. Kemenkes-RI. Standar Pelayanan Keperawatan ICU di Rumah Sakit. Jakarta: Direktorat Bina Keperawatan dan Keteknisian Medik. Direktorat Jenderal Bina Upaya Kesehatan; 2011.

5. Kemenkumham-RI. Undang-undang Republik Indonesia Nomor 38 Tahun 2014 tentang Keperawatan. Jakarta: Kementerian Hukum dan Hak Asasi Manusia; 2014.

6. RI DK. Standar pelayanan keperawatan di ICU. Jakarta: Direktorat keperawatan dan keteknisian medik direktorat jenderal pelayanan medik; 2006.

7. Kollef MH, Shapiro SD, Silver P, et al. A randomized, controlled trial of protocol directed versus physician-directed weaning from mechanical ventilation. Crit Care Med. 1997;25:567-574.

8. Blackwood B, Alderdice F, Burns KEA, Cardwell CR, Lavery GG, O'Halloran P. Protocolized vs. nonprotocolized weaning for reducing the duration of mechanical ventilation in critically ill adult patients: Cochrane review protocol. Journal of Advance Nursing. 2009;65(5):957-964.

9. Henneman E, Dracup K, Ganz T, Molayeme O, Cooper C. Effect of a collaborative weaning plan on patient outcome in the critical care setting. Crit Care Med. 2001;29(2):297-303.

10. Tonnelier J-M, Prat G, Gal GL, et al. Impact of a Nurses' protocol-directed weaning procedure on outcome in patients undergoing mechanical ventilation for longer than 48 hours: a prospective cohort study with a matched historical control group. Critical Care. 2005;9:83-89.

11. Blackwood B, Alderdice F, Burns K, Cardwell C, Lavery G, O'Halloran P. Use of weaning protocol for reducing duration of mechanical ventilation in critically ill adult patients: Cochcrane systematic review and meta-analysis. BMJ. 2011;342.

12. Roh JH, Synn A, Lim CM, et al. A weaning protocol administered by critical care nurses for the weaning of patients from mechanical ventilation. Journal of critical care. 2012;27:549-555.

13. Dankers M, Grosu H, Jean R, et al. Nurse-driven, protocol-directed weaning from mechanical ventilation improve clinical outcome and is well accespted by intensive care unit physician. journal of Critical Care. 2013;38:433-441.

14. Girard TD, Ely EW. Protocol-driven ventilator weaning : Reviewing the evidence. Clin Chest Med 2008;29:241-252. 
15. Black CJ, Kuper M, Bellingan GJ, Batson S, Matejowsky C, Howel DC. A multidiciplinary team approach to weaning from prolonged mechanical ventilation. British Journal of Hospital Medicine. 2012;73(8):462-466.

16. Rose L, Nelson S, Johnston L, Presneill JJ. Decisions made by critical care nurses during mechanical ventilation and weaning in an Australian intensive care unit. American Journal of Critical Care. 2007;16 (5):434-443. 